\title{
Avaliação do letramento digital de alunos ingressantes do ensino superior: uma abordagem exploratória do conhecimento computacional, comunicacional e informacional
}

\footnotetext{
Universidade Norte do Paraná, (Unopar), Londrina, Paraná, Brasil. E-mail: <helio. suguimoto@unopar.br >; $<$ http://orcid.org/0000-00028461-3079>.

II Doutor em Ciência de Alimentos pela Universidade Estadual de Londrina (UEL), Londrina, Paraná, Brasil.

III Universidade Norte do Paraná (Unopar), Londrina, Paraná, Brasil. E-mail: <anderson. rolim@unopar.br>; <http:// orcid.org/0000-0003-44644249>.

IV Doutor em Letras pela Universidade Estadual de Londrina(UEL), Londrina, Paraná, Brasil.

v Universidade Norte do Paraná (Unopar), Londrina, Paraná, Brasil. E-mail: <bernalema@ gmail.com>; <http://orcid. org/0000-0002-5041-4629>.

vi Doutora em Linguística pela Universidade de São Paulo (USP), São Paulo, Brasil.

vil Universidade Norte do Paraná, (Unopar), Londrina, Paraná, Brasil. E-mail: <flavio@caputconsultoria. com.br >; <http://orcid.org/ 0000-0002-9135-3316>.

VIII Mestre em Ensino pela Universidade Norte do Paraná (Unopar), Londrina, Paraná, Brasil.
}

Hélio Hiroshi Suguimoto ${ }^{\mathrm{I}, \text { II }}$

Anderson Teixeira Rolim ${ }^{\mathrm{III}, \mathrm{IV}}$

Bernadete Lema Mazzafera ${ }^{\mathrm{V}, \mathrm{vI}}$

Flavio Aparecido Antonio Franco de Moura ${ }^{\mathrm{VII}, \mathrm{VIII}}$

http://dx.doi.org/10.24109/2176-6681.rbep.98i250.3011

\section{Resumo}

Este artigo analisa o letramento digital de alunos ingressantes no ensino superior, destacando os aspectos do conhecimento computacional, comunicacional e informacional. Realizou-se uma pesquisa descritiva exploratória quantitativa analítica e, como técnica específica para obter as informações requeridas, utilizou-se um questionário composto por 12 questões sobre aspectos relacionados à competência computacional, comunicacional e informacional, adaptadas dos estudos de Ribeiro e Behar (2013), além de campos referentes ao perfil dos respondentes. Nesta pesquisa, que obteve 410 respostas, foi possível verificar a associação entre idade e conhecimento computacional, conhecimento comunicacional e conhecimento informacional. Os discentes mais jovens possuíam maior conhecimento nas dimensões pesquisadas, segundo o Teste de MannWhitney $(p<0,05)$. Não houve diferenças entre as Regiões Centro-Oeste e Nordeste, locais das pesquisas. Evidenciou-se que o conhecimento de programas de computador não implicava domínio das ferramentas computacionais inerentes a eles. Não houve correlação entre conhecer 
programas computacionais e possuir habilidades computacionais. Ademais, $8 \%$ de ingressantes do ensino superior não possuíam conhecimento acerca de qualquer programa computacional, e 18\% dos respondentes declararam ter dificuldades para localizar informações.

Palavras-chave: alunos; ensino superior; letramento digital.

\section{Abstract \\ Digital literacy assessment of students entering higher education: an exploratory approach to the computational, communicative and informational knowledge}

This paper analyzes digital literacy in students entering higher education, highlighting aspects of the computational, communicative and informational knowledge. It was conducted an analytical quantitative descriptive exploratory research and, as a specific technique to collect data, a questionnaire with 12 questions was designed about on aspects related to the computational, communicative and informational skill, adapted from studies by Ribeiro and Behar (2013), with fields about the profile of the participants. This study, in which 410 answers were gathered, found that there is a relation between age and the computational, communicative and informational knowledge. Younger students were more knowledgeable in the surveyed areas, according to Mann-Whitney test $(p<0.05)$. When it comes to the places in which the research took place, was found no difference between the midwest and the northeast regions. Moreover, a knowledge of computer programs does not imply mastery of their computational tools. No correlation was found between knowing computer programs and having computational skills. Thus, eight percent of freshmen in higher education had no knowledge of computer programs and eighteen percent of the participants reported difficulties to find digital information.

Keywords: students; higher education; digital literacy.

\section{Introdução}

Partindo do pressuposto de que a tecnologia contribui para o processo de ensino e aprendizagem, é fundamental que se compreenda a relação entre esse processo e as tecnologias digitais da informação e comunicação (TDIC). Do mesmo modo, educadores podem auxiliar os alunos a compreenderem e dominarem o letramento ${ }^{1}$ digital na era da informática.

Para Warschauer (2006), existem três tipos distintos de organização metodológica que se conectam à tecnologia e à educação, os quais são

\footnotetext{
Neste trabalho, o fenômeno do letramento, tendo como instrumento a tecnologia digital, será compreendido como propõem Micarello e Magalhães (2014, p. 150): "O fenômeno do letramento deve ser compreendido, para além da posse de novas tecnologias do ler e escrever, como a assunção pelos sujeitos de um posicionamento frente ao mundo".
} 
autoexplicativos: educação por via da informática, educação reforçada pela informática e educação a distância.

A Associação Europeia para a Garantia da Qualidade no Ensino Superior (European Association for Quality Assurance in Higher Education - ENQA) publicou um projeto - resultante de fórum realizado na Suécia em 2009 -, que apresenta experiências de vários países, a fim de garantir a qualidade do ensino ministrado a distância. No prefácio, o presidente da ENQA, Achim Hopbach, declara que, como o aprendizado baseado na internet é atualmente um tema tão relevante, "há uma extrema necessidade de criação de uma linguagem e orientações comuns entre todos para de forma coletiva proceder positivamente em relação ao desenvolvimento [de] uma cultura de qualidade dentro do quadro de e-learning" (Grifoll et al., 2010, tradução nossa).

Nas conclusões do documento, há o reconhecimento de que o e-learning (ensino eletrônico apoiado em tecnologias digitais) tornou-se um método pedagógico particularmente atraente com o uso de ferramentas baseadas na rede mundial de computadores, o que reduz custos, barreiras de comunicação e distância geográfica entre os indivíduos. Além disso, aumenta a mobilidade acadêmica no ensino superior, proporciona melhor acesso às pessoas com deficiência e permite que instituições menores ganhem visibilidade mediante programas de estudo on-line. Porém, também são apresentados no documento os desafios que envolvem as instituições que fornecem programas de ensino a distância e a responsabilidade dos docentes que participam desses cursos, destacando-se a dependência das tecnologias digitais de informação e comunicação (TDIC) e das ferramentas de aprendizagem (Grifoll et al., 2010, tradução nossa).

Belloni (2005), referindo-se ao trabalho realizado por Milta Torrez sobre educação a distância para profissionais da saúde, destaca que essa modalidade pode representar uma democratização da educação e da formação profissional. A modalidade cria

[...] sinergias positivas entre o ensino presencial e a distância, na medida em que as inovações educativas exigidas pela educação a distância (técnicas, métodos, organização) acabam influenciando positivamente o ensino presencial, na formação inicial e continuada. (Belloni, 2005, p. 188).

Entre os aspectos positivos mais evidentes da integração de inovações tecnológicas nos processos de ensino, está a individualização dos caminhos de aprendizagem por meio da pesquisa mediada por sistemas de busca on-line. O acesso a esses mecanismos de comunicação e informação caracteriza-se por uma nova concepção de espaço. Os limites da informação e da comunicação, antes demarcados pela realidade geográfica, virtualizam-se no salto hipertextual da experiência de navegação na world wide web. O mesmo é válido para a educação a distância. Segundo Belloni, a "educação a distância é um conceito que enfatiza a dimensão espacial, ou seja, a separação física entre o professor e o aluno, e a dimensão de massa da produção e distribuição de materiais" (Belloni, 2005, p. 190). 
Esse diferente relacionamento com o espaço de aprendizagem e com o acesso a materiais diversos dá autonomia e flexibilidade na execução de atividades acadêmicas. A aprendizagem aberta enfatiza a adequação "de um processo de educação mais autônomo e flexível, de maior acessibilidade aos estudantes, o que significa, sobretudo, a expansão de novas modalidades de ensino e de novas regras de acesso e pré-requisitos de ingresso" (Belloni, 2005, p. 190).

O pré-requisito para um processo eficaz de aprendizado por e-learning é que os alunos tenham competências suficientes em TDIC. Soma-se a isso o comprometimento dos desenvolvedores de aplicativos, programas e sistemas em rede com a implementação de estratégias educativas adequadas para gerir caminhos de aprendizagem a distância.

De acordo com Behar et al. (2013, p. 20), "a perspectiva das competências como possibilidade de formação integral do indivíduo surge como uma alternativa para a educação". As autoras alertam que existem resistências e críticas em relação ao uso do termo "competência" por sua associação com o vocábulo "competição". Para as autoras, as competências são "um conjunto de elementos compostos pelos Conhecimentos, Habilidades e pelas Atitudes" (Behar et al., 2013, p. 23).

O e-learning é eficiente desde que o conteúdo de aprendizagem seja atualizado regularmente e a metodologia de ensino utilizada nos programas a distância ajude os alunos a dominar o material de aprendizagem e a aquisição de conhecimentos (Grifoll et al., 2010, tradução nossa) necessários para o desenvolvimento de competências na área de interesse.

\begin{abstract}
Na literatura da ciência da informação no Brasil, "competência" é frequentemente empregada como sinônimo de letramento informacional. Todavia, competência refere-se àquilo que se deseja construir e desenvolver ao longo de um processo, no caso o de letramento informacional. Assim, propõe-se que competência seja utilizada como expressão do "saber-fazer", derivada das relações entre o conhecimento que o sujeito detém, a experiência adquirida pela prática e a reflexão sobre a ação (Gasque, 2003). Por sua vez, habilidade é a realização de cada ação específica e necessária para alcançar determinada competência (Gasque, 2010, p. 88).
\end{abstract}

Inicialmente, o letramento digital pode ser definido como conhecimento e habilidade necessários para atuar com dispositivos eletrônicos. Tal conhecimento e tal habilidade geralmente incluem letramentos alfabéticos, bem como a compreensão elementar da interface de um computador e algum conhecimento especializado em efetivação de comandos, como salvar um documento, imprimi-lo ou enviá-lo por uma rede (Jenkins, 2010).

Letramento digital significa também possuir os conhecimentos e as habilidades para decodificar símbolos e torná-los providos de significado e propósito. Uma interface de manipulação icônica e direta, por exemplo, exige a capacidade de o usuário compreender seu sistema de símbolos e ser capaz de prever com segurança as consequências de certas ações que, como usuário, ele precisa fazer, como rolar um texto para trazer algum detalhe à vista (Jenkins, 2010). 
A cultura digital é o conjunto de conhecimentos, habilidades e comportamentos usados em uma ampla gama de dispositivos digitais, como smartphones, tablets, laptops e computadores de mesa, os quais são vistos como parte de uma rede mais ampla, em vez de meros dispositivos de computação (Lemos, 2007).

Originalmente, o letramento digital estava focado em competências digitais e na operação isolada de computadores, todavia o foco passou do isolamento e da singularidade dos dispositivos para o uso dos equipamentos em rede. Isso implica que o letramento digital é diferente de conhecimentos e competências informacionais digitais. Conhecimentos de informática precedem o letramento digital e referem-se ao conhecimento e às habilidades no uso de computadores tradicionais, tais como computadores pessoais, com foco em habilidades práticas no uso de pacotes de aplicativos de software. Competências digitais é uma expressão mais contemporânea, mas também se limita a habilidades práticas no uso de dispositivos digitais (Lemos, 2007; Lévy, 2008).

Um indivíduo imerso na cultura digital deverá possuir uma gama de competências, como conhecimento dos princípios básicos dos dispositivos, habilidades para usar redes de computadores, capacidade de se envolver em comunidades on-line e redes sociais ao aderir a protocolos comportamentais, capacidade de encontrar, capturar e avaliar a informação, de compreender as questões sociais levantadas pelas tecnologias digitais e de possuir pensamento crítico (Proulx, 2016).

Desse modo, é possível afirmar que a cultura digital se decompõe em um novo letramento, que pode ser dividido em outros letramentos. Assim, o letramento digital se traduziria, em última instância, pelo letramento para o uso dos dispositivos digitais, da rede, da informação e da mídia social. Incluem-se aí os conhecimentos básicos de hardware e suas conexões e de software, por exemplo, o uso de pacotes de aplicativos para ações específicas, como editar um texto, uma foto ou um vídeo (Proulx, 2016).

Noutro sentido, acepções contemporâneas de letramento digital também consideram habilidades, atitudes e comportamentos particularmente voltados para a utilização de dispositivos de rede, móveis ou não, como tablets e smartphones. A troca de perspectiva é significativa: enquanto, no passado, tratava-se das habilidades práticas que o conhecimento de informática incorporava, na atualidade há um foco maior sobre os aspectos sociológicos, políticos, culturais, econômicos e comportamentais que envolvem o uso das tecnologias digitais (Gillen, 2016; Zhao; Kynäshlahti; Sintonen, 2016). A internet é uma fonte de informação e comunicação que tem aumentado exponencialmente. A integração da tecnologia nos processos de ensino e aprendizagem expõe os alunos a uma série de práticas de multiletramentos que ampliam suas perspectivas acerca da informação e do conhecimento (Rojo, 2009).

O desenvolvimento das competências essenciais ao letramento digital, relacionadas aos contextos particulares em que cada indivíduo as desenvolve, enfatiza elementos distintos desse letramento. De acordo com Belshaw (2012) e Bawden (2008), o letramento digital se constitui na 
confluência de oito tipos de elementos: cultural, cognitivo, construtivo, comunicativo, crítico, cívico, criativo e autoconfiante.

O elemento cultural do letramento digital requer o uso da tecnologia em diferentes contextos e uma consciência dos valores e conceitos específicos para esses contextos. O elemento cognitivo visa a permitir o domínio do uso de ferramentas e plataformas tecnológicas. O elemento construtivo exige a reutilização e o remix dos recursos existentes. Por meio da construção, o indivíduo inserido na cultura digital cria novos dados e compartilha suas criações. O elemento comunicativo requer consciência sobre os diferentes dispositivos de comunicação digitais e móveis. O letramento em mídias digitais implica um modelo de comunicação que se desdobra no uso de diferentes aplicativos. O elemento de autoconfiança revela-se na capacidade de criar um ambiente para a autoaprendizagem. O elemento criativo estimula os alunos a criarem novos dados em ambientes digitais com base em interesses pessoais. Esse elemento dá ênfase ao desenvolvimento de habilidades de pesquisa e à criação de produtos. O componente crítico exige que o aluno digital seja capaz de desenvolver perspectivas diversas. Enquanto participam ativamente em ambientes digitais, os usuários devem tomar diferentes circunstâncias em consideração para o desenvolvimento de suas atividades, de novos produtos e de interações sociais. O elemento cívico refere-se ao desenvolvimento e à aquisição dos conceitos de democracia e cidadania global por intermédio de tecnologias digitais. Esse componente ajuda na participação do indivíduo na sociedade, pois parte do letramento digital está na capacidade de formar e/ou participar de comunidades online. (Belshaw, 2012; Bawden, 2008).

A incorporação desses elementos nas práticas sociais exige constante atualização, pois a informação e as ferramentas digitais mudam junto com a nossa compreensão sobre elas. Desse modo, do ponto de vista pedagógico, o letramento digital visa a incluir o conhecimento e a compreensão das aplicações e implicações sociais das tecnologias digitais, em contraste com as habilidades que têm foco apenas em conhecimentos informáticos.

Marc Prensky (2001) inventou e popularizou as expressões "nativos digitais" e "imigrantes digitais". Um nativo digital, para Prensky, é aquele que nasceu na era digital. Um imigrante digital, portanto, é aquele que adota mais tarde a tecnologia na vida. As expressões ajudam a compreender as questões de letramento informático; no entanto, o fato de simplesmente ser um nativo digital não se traduz no pertencimento a uma cultura digital. Os imigrantes digitais, apesar de se adaptarem à mesma tecnologia que os nativos, possuem uma espécie de sotaque que lhes restringe a comunicação na forma como os nativos a realizam (Prensky, 2001). Franco (2013) realizou pesquisa para melhor compreender as perspectivas denativos digitais sobrea aprendizagem de inglês, utilizando a expressão "nativo digital" com base em extensa revisão: ${ }^{2}$

[...] para referir-se a alunos que não apenas nasceram num mundo rodeado pela tecnologia digital, mas que também fazem uso da mídia digital como parte integrante de suas vidas. Sob nenhuma circunstância,

\footnotetext{
Baseado em uma revisão abrangente da literatura (Gasser; Cortesi; Malik; Lee, 2012; Jukes; McCain; Crockett, 2010; Miller, 2011; Palfrey; Gasser, 2008; Prensky, 2001a, 2001b, 2006, 2010, 2012) e em minhas próprias observações como professor, as seguintes características podem ser identificadas entre os nativos digitais: vivem no mundo dos computadores e dos videogames; estão constantemente ligados ao mundo on-line; possuem a capacidade de utilizar a tecnologia digital de forma transparente; eles se expressam de maneiras mediadas por tecnologias digitais (principalmente mediadores de conexões humano-humanas); eles têm muitos amigos em sites de redes sociais (incluindo pessoas que nunca conheceram pessoalmente); eles se sentem confortáveis em espaços on-line; eles dependem de espaços online para procurar todas as informações de que necessitam (aprendematravés da navegação); eles têm uma tendência para atender a várias coisas ao mesmo tempo - multitarefa; recebem e processam informações a um ritmo rápido; eles compartilham fotos e vídeos com seus amigos em todo o mundo." (Franco, 2013, p. 644-645).
} 
eu suponho que eles são superiores ou inferiores às pessoas da geração anterior, os "imigrantes digitais", que se refere àqueles nascidos antes do boom da tecnologia digital. (Franco, 2013, p. 645).

Nesse sentido, é possível afirmar que, devido à natureza flexível do nosso cérebro, a tecnologia já mudou a forma como os estudantes de hoje leem, percebem e processam informações (Carr, 2008). Isso significa que os educadores de hoje podem ter dificuldades para encontrar métodos de ensino eficazes para nativos digitais. Prensky (2001) acredita que esse é um problema porque os estudantes de hoje, para se comunicarem, possuem uma linguagem nova, se comparada àquela dos que os educaram. Incluem-se aí os termos específicos utilizados nos ambientes digitais e a cultura memética (Blackmore, 1999).

Para Warschauer (2006, p. 25), "a capacidade de acessar, adaptar e criar novo conhecimento por meio do uso da nova tecnologia de informação e comunicação é decisiva para a inclusão social na época atual". O autor cita os estudos de Robison e Crenshaw, realizados em 2000 em diversos países, nos quais a educação em massa se relaciona "diretamente com os níveis mais elevados de acesso à internet pela sociedade" (Warschauer, 2006, p. 151). Compreende-se que "a educação em massa não é apenas causa do desenvolvimento econômico, mas também consequência" (Warschauer, 2006, p. 153).

O processo educacional determina como as pessoas utilizam a internet e os benefícios advindos desse uso. A utilização apropriada da internet demanda uma associação entre tecnologia e letramento digital. O trio informação, conhecimento e aprendizagem define a sociedade contemporânea e, por conseguinte, suscita demandas educacionais alinhadas a esses elementos.

Silva (2012, p. 4), ao realizar um estudo que reflete sobre os conceitos de letramento digital e discute a formação docente, afirma que ser letrado em ambiente digital é realizar "práticas de leitura e escrita que diferem das práticas tradicionais. É saber pesquisar, selecionar, utilizar as diversas ferramentas disponíveis para cumprir propósitos variados, é se relacionar com seus pares $[\ldots]^{\prime \prime}$.

Letramento digital, como discutido e abordado nesta pesquisa, é uma expressão geral que inclui diferentes modalidades de letramento: letramento via computador, letramento informacional, multimídia e comunicacional mediado por computador (Warschauer, 2006, p. 154). Para Warschauer, "esses novos letramentos originam-se, em parte, dos novos aspectos tecnológicos associados ao computador, mas também do cenário social mais amplo em que os computadores são usados" (Warschauer, 2006, p. 154).

Behar et al. (2013) argumentam que na sociedade "conectada" ou sociedade da informação exige-se cada vez mais um tipo de indivíduo que seja letrado digitalmente. Nesse cenário, profissionais oriundos do ensino superior devem lidar com novidades e descobertas científicas e tecnológicas que se traduzem em incertezas. Assuntos complexos e inéditos são discutidos frequentemente nos ambientes de trabalho (Behar et al., 2013). 
Os autores complementam dizendo que ser alfabetizado digital diz respeito a aprender a usar o computador e periféricos de forma básica, por meio de comandos básicos, ao passo que o letramento significa dominar e utilizar a tecnologia em termos práticos, "permitindo que o indivíduo interprete, compreenda, atue e produza nesse universo" (Behar et al., 2013, p. 39).

Reflexo dessa tendência, a busca crescente por profissionais de tecnologia da informação (TI) é um termômetro do contexto. O estudo da consultoria IDC Brasil (2016) demonstrou que, na contramão de setores mais tradicionais da economia, a contratação de profissionais de TI deveria crescer 2,6\% em comparação com o ano anterior.

Nesse contexto, a formação de profissionais que respondam às demandas ocorre no ensino superior. Na Lei de Diretrizes e Bases da Educação Nacional (Lei n 9.394/1996), o parágrafo II do artigo 43 estabelece que uma das finalidades da educação superior é a formação de profissionais nas diversas áreas do conhecimento, aptos para atuar no desenvolvimento da sociedade e em seu melhoramento contínuo (Brasil, 1996).

Reconhecer as condições reais de acesso à informação e à comunicação digital de alunos ingressantes no ensino superior é essencial para a criação e o desenvolvimento de estratégias adequadas à formação que contemplem as demandas associadas ao uso das TDIC. Desse modo, o objetivo deste artigo é avaliar o letramento digital de alunos ingressantes no ensino superior, destacando os aspectos do conhecimento computacional, comunicacional e informacional.

\section{Método}

Para responder à questão proposta, realizou-se uma pesquisa descritiva exploratória quantitativa analítica, motivada pelas dúvidas dos ingressantes quanto ao uso das TDIC, apontadas pelos coordenadores de cursos que participaram da pesquisa, na instituição em que os pesquisadores deste estudo atuam como professores. Como técnica específica para obter as informações requeridas, foi utilizado um questionário composto por 12 questões sobre aspectos relacionados à competência computacional, comunicacional e informacional, adaptadas dos estudos de Ribeiro e Behar (2013), além de campos para coletar dados referentes ao perfil dos respondentes. As perguntas versaram sobre: a) utilização ou não dos programas Word, Excel, Powerpoint e BrOffice; b) habilidade para instalar e desinstalar programas e encontrar arquivos e programas; c) utilização ou não de e-mail, Facebook, Twitter e Skype; d) conhecimento sobre busca de informação e dificuldades ou não em utilizar dois sites de busca (G1 e UOL) e o Youtube.

Para assegurar uma amostra probabilística aleatória simples da população-alvo, que atribui a cada elemento da população igual chance de seleção, elegeram-se de forma aleatória acadêmicos de cinco unidades da instituição em que trabalhavam e atuavam os pesquisadores. Os questionários foram aplicados no período de novembro a dezembro de 
2014 em quatro unidades da instituição: uma no Maranhão, duas na Bahia e uma em Mato Grosso.

Os dados foram analisados quantitativamente utilizando-se o software GraphPad Prism 5.0 (San Diego, CA, EUA), tendo sido estabelecido intervalo de confiança de $95 \%$ e nível de significância de 5\% para todos os testes aplicados $(p<0,05)$. Utilizou-se o Teste de Mann-Whitney para comparação dos conhecimentos computacional, comunicacional e informacional entre as faixas etárias, assim como para a comparação das mesmas variáveis entre as regiões. Além disso, utilizou-se a Correlação de Spearman para avaliar possível associação entre os conhecimentos e as habilidades computacionais.

\section{Resultados e discussões}

Foram aplicados 414 questionários, compostos por 12 questões. Excluindo-se os sujeitos que não informaram a idade, houve participação de 410 respondentes. Em relação ao perfil desses, 76\% são mulheres egressas do sistema público de ensino, e a mediana de idade foi de 30 anos.

A proporção de brasileiros entre 25 e 34 anos que concluíram o ensino superior quase dobrou entre 2004 e 2013, passando de 8,1\% para $15,2 \%$ (um a cada sete brasileiros). O índice é o mais baixo entre os países participantes da Organização de Cooperação e Desenvolvimento Econômico (OCDE) (Capuchinho, 2014). Comparando a mediana de idade desta pesquisa com a idade dos alunos do ensino superior de outros países, tem-se que, na União Europeia, com 28 Estados-membros, a média - calculada com base em dados referentes a 2012 - varia de 25 anos na Finlândia a 20,4 anos na Irlanda (Pordata, 2016). Assim, a mediana de idade desta pesquisa sugere um desafio no processo educacional do País.

Em relação ao fato de as mulheres serem maioria nesta pesquisa, há concordância com os dados do Instituto Nacional de Estudos e Pesquisas Educacionais Anísio Teixeira (Inep): "o percentual médio de ingresso de alunas até 2013 foi de 55\% do total em cursos de graduação presenciais. Se o recorte for feito por concluintes, o índice sobe para 60\%" (Portal Brasil, 2015).

Ribeiro e Behar (2013), tratando das "Competências para o letramento digital", elaboraram, por meio de revisão de literatura, um mapeamento preliminar para explicar os conhecimentos, as habilidades e as atitudes necessários para o letramento digital. Baseando-se nos estudos de Warschauer (2006), estabeleceram quatro categorias de competências: computacional, comunicacional, multimídia e informacional.

Cada uma das competências foi subdividida em conhecimento, habilidades e atitudes em função das atividades realizadas. Na presente pesquisa, destacou-se a competência computacional, que se relaciona aos conhecimentos básicos para o uso do computador, de acordo com o conjunto de conhecimentos e habilidades proposto pelas autoras; a competência comunicacional, que se relaciona às expressões oral, gestual e escrita; e a 
competência informacional, que se relaciona à busca, avaliação e utilização de informações no aspecto conhecimento (Ribeiro; Behar, 2013).

Em relação aos conhecimentos para utilização de programas de computador, 34 respondentes relataram não possuir conhecimento sobre esses programas; 71 relataram conhecer um programa; 102, dois programas; 155, três programas; e 48, quatro programas. No Gráfico 1, os números de 0 a 4 referem-se à quantidade de programas de computador que os participantes afirmaram conhecer. O teste de Mann-Whitney compara os resultados em relação à mediana de idade desta pesquisa (30 anos). Verifica-se que, na faixa etária de até 30 anos, há predomínio de conhecimento de mais de dois programas de computador e, na faixa etária de maiores de 30 anos, há predomínio de conhecimento de até dois programas de computador.

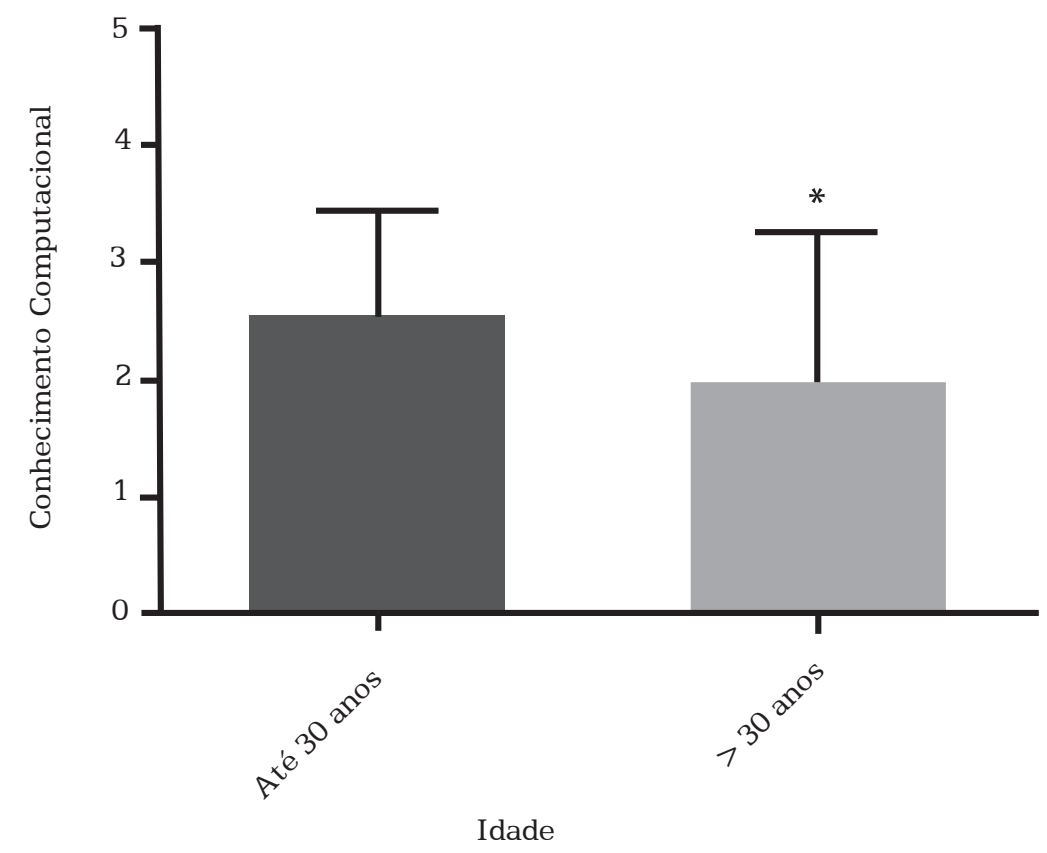

\section{Gráfico 1 - Comparação do Índice de Conhecimento Computacional em Relação à Faixa Etária}

Fonte: Elaboração própria.

*Estatisticamente significante, Teste de Mann-Whitney, $\mathrm{p}=0,0001$.

Excluindo-se as respostas dos que relataram nunca ter utilizado qualquer programa computacional, analisaram-se as respostas de 376 respondentes em relação às habilidades computacionais para encontrar arquivos, instalar e desinstalar programas: 59\% dos respondentes informaram não possuir habilidade para instalar e desinstalar programas e $26 \%$ informaram não possuir habilidade para encontrar arquivos e programas. 


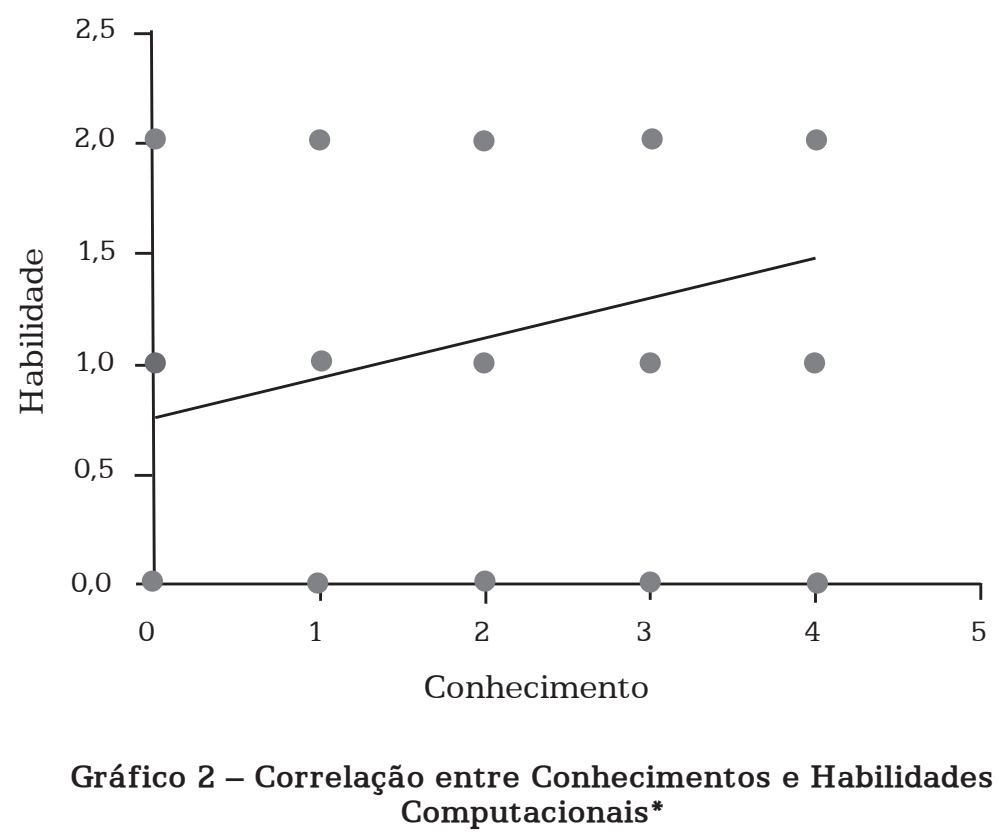

Fonte: Elaboração própria.

${ }^{*}$ Estatisticamente significante, Correlação de Spearman ( $\left.r S=0,27\right), p=0,0001$.

Há correlação fraca entre os dados de conhecimentos e habilidades computacionais. Quando se avaliam esses itens pelo Teste de Concordância de Kappa, não há concordância ( $\mathrm{p}=0,73)$. Há uma tendência de os indivíduos com mais conhecimento terem maior habilidade computacional. Entretanto, nem todos que relatam ter conhecimento afirmaram possuir as habilidades pesquisadas.

Segundo Kleiman (2014), para falar de letramentos na contemporaneidade, é preciso tratar de letramento digital. Colocar em pauta a questão do letramento digital no Brasil também é tratar das questões que permeiam o letramento impresso e os diferentes tipos de analfabetismo que, infelizmente, ainda são observados em grandes grupos sociais, pois o conhecimento distingue-se da habilidade em utilizar apropriadamente um programa de computador. A habilidade consiste em saber nomear um programa e compreender o significado de seu nome, o que engloba a compreensão da utilidade do programa e a experiência na utilização dele.

Bandeira (2009), tratando das trajetórias de estudantes universitários de meios populares em busca de letramento digital, por meio de pesquisa qualitativa com alunos ingressantes universitários, relata que há a expectativa de que esses alunos dominem a TDIC ao ingressarem no ensino superior. Mais ainda, a pesquisa referia-se à constatação de Kleiman de que "ser letrado digital é saber fazer o uso social da leitura e da escrita na tela, dentro de contextos em que tais práticas são necessárias ao indivíduo [...]" (Bandeira, 2009, p. 226-227).

Ricoy e Couto (2014) relatam que, nas instituições de ensino superior, a infraestrutura tecnológica foi incrementada nos últimos dez anos. No 
entanto, em estudo realizado na Espanha, os autores dizem que "no âmbito educativo, o uso de boas práticas avança lentamente. De fato, em muitos casos, a aplicação das TIC encontra-se imersa em dinâmicas tradicionais" (Ricoy; Couto, 2014, p. 899).

Em relação aos instrumentos que fazem a mediação comunicacional, em que se aplica o conhecimento sobre netiqueta: "conjunto de práticas para a comunicação próprias da internet" (Ribeiro; Behar, 2013, p. 222), as aplicações on-line mais utilizadas pelos respondentes são o Facebook, citado por $87 \%$, e o e-mail, citado por $93 \%$. Os itens de 0 a 4 revelam o conhecimento solicitado na pesquisa: 13 participantes da pesquisa nunca utilizaram e-mail, Facebook, Twitter ou Skype; 37 utilizaram uma dessas ferramentas de comunicação; 195, duas ferramentas; 88, três ferramentas; e 77 participantes disseram utilizar as quatro ferramentas de comunicação.

Para Warschauer (2006, p. 162), o letramento comunicacional mediado pelo computador, "em um nível mais sofisticado, inclui a pragmática da argumentação e da persuasão eficaz em diversos tipos de mídia da internet [...]. Em nível mais sofisticado [...] inclui o know-how para estabelecer e administrar as comunicações on-line".

Na pergunta sobre a dificuldade em buscar informações no computador, 337 respondentes (82\%) afirmaram não ter dificuldade e 73 respondentes (18\%) declararam ter dificuldade. Para as perguntas que abordaram as dificuldades em utilizar dois sites de busca (G1 e UOL) e o Youtube, obtivemos as seguintes respostas: 41 respondentes tinham dificuldades em utilizar qualquer site de busca; 39, em encontrar informações em um site; 72, em encontrar informações em dois sites; e 258, em navegar e encontrar informações nesses três sites.

Desde a popularização da internet em meados dos anos 1990, o crescimento e o acesso têm sido amplos e pouco previsíveis em relação à demanda (Costa; Bianchini, 2008). Em mapeamento sobre a utilização da internet, os autores identificaram que, entre os fatores que têm contribuído para o aumento do uso da internet, o principal é a busca pelo conhecimento. Além de amparar a disseminação e a socialização do conhecimento, a internet é uma maneira de facilitar o contato entre o usuário e o conteúdo (Costa; Bianchini, 2008, p. 157).

A busca de informações é uma habilidade integrante do letramento informacional. Localizar, avaliar e utilizar as informações mediante as TDIC inclui-se na capacidade de desenvolver boas perguntas de pesquisa; determinar os lugares de busca das informações; selecionar ferramentas de busca; avaliar o resultado e a confiabilidade das informações; salvar e arquivar as informações localizadas, além de referenciá-las (Warschauer, 2006, p. 157). Nesta pesquisa, os resultados indicam que possivelmente há comprometimento na busca e análise das informações na internet pelos estudantes. De acordo com Warschauer (2006), os letramentos informacionais compreendem conhecimentos específicos quanto ao uso do computador e habilidades de letramento mais amplas, tais como: analisar e avaliar as fontes de informação. 
Em um estudo de revisão, Gasque (2010) afirma que muitos são os termos e conceitos relacionados à information literacy, expressão surgida na década de 1970 nos EUA. Segundo a autora, a intensificação das pesquisas sobre letramento informacional no Brasil data desse período. Gasque cita os estudos de Duzdiak (2003) acerca das diferentes concepções, de acordo com a ênfase e o contexto de utilização da expressão information literacy: "ênfase na tecnologia da informação (concepção da informação), ênfase nos processos cognitivos (concepção cognitiva) e ênfase no aprendizado (concepção da inteligência)" (Gasque, 2010, p. 84). A autora destaca que, em uma concepção cognitiva, o "letramento informacional é compreendido como processo de busca de informação para a aquisição do conhecimento" (Gasque, 2010, p. 84).

Comparando-se as duas regiões (Nordeste e Centro-Oeste) das unidades que fizeram parte deste estudo e as modalidades de conhecimento pesquisadas, não houve diferença entre discentes de até 30 anos de idade e discentes de idade superior (Teste de Mann-Whitney, $p>0,05$ ). Acredita-se que a pesquisa contribui para reflexões sobre o processo de formação do aluno oriundo da escola pública, que representa $76 \%$ dos participantes desta pesquisa, no que diz respeito ao conhecimento computacional, comunicacional e informacional.

\section{Conclusão}

Nesta pesquisa foi possível verificar que há associação entre idade e conhecimento computacional, conhecimento comunicacional e conhecimento informacional, de modo que os discentes mais jovens possuem mais conhecimentos. Não se constataram diferenças regionais quanto ao domínio desses conhecimentos.

Também se observou que o conhecimento de programas de computador não implica domínio das ferramentas computacionais inerentes a eles. Assim, não há correlação entre conhecer programas computacionais e possuir habilidades computacionais.

Nesta pesquisa, $8 \%$ de ingressantes do ensino superior não possuem conhecimento sobre qualquer programa computacional, e $18 \%$ dos respondentes declararam ter dificuldades para localizar informações.

O ensino superior apresenta situações que demandam um processo de construção de conhecimento que proporcione autonomia no processo de apreender, para que se efetivem as finalidades desse nível no Brasil, em conformidade com o que está preconizado na Lei de Diretrizes e Bases da Educação Nacional (Lei n 9.394/1996). Nesse cenário, o conhecimento e o domínio de ferramentas de TI são fundamentais para o desenvolvimento de estratégias de ensino que se traduzam na formação de profissionais capazes de atuar na construção e no aprimoramento da sociedade brasileira. De modo específico, numa sociedade que se quer moderna, são imperativas as ações para a diminuição dos índices de dificuldades computacionais, comunicacionais e informacionais. 


\section{Referências bibliográficas}

BANDEIRA, D. P. Trajetórias de estudantes universitários de meios populares em busca de letramento digital. 2009. $279 \mathrm{f}$. Tese (Doutorado em Educação) - Faculdade de Educação, Universidade Federal de Minas Gerais, Belo Horizonte, 2009. Disponível em: <http://www. bibliotecadigital.ufmg.br/dspace/handle/1843/FAEC-83VSS5>. Acesso em: 12 maio 2016.

\section{BASE DE DADOS PORTUGAL CONTEMPORANEO (PORDATA). Idade} média dos alunos no ensino superior (ISCED 5-8) (1998-2012). 2016. Disponível em: <http://www.pordata.pt/Europa/Idade+m\%C3\%A9dia+ dos +alunos +no +ensino +superior +(ISCED +5+8) +(1998+2012)-1310 > . Acesso em: 18 ago. 2016.

BAWDEN, D. Origins and concepts of digital literacy. In: LANKSHEAR, C.; KNOBEL, M. Digital literacies: concepts, policies and practices. New York: Peter Lang, 2008. p. 17-32.

BEHAR, P. A. et al. Competência: conceito, elementos e recursos de suporte, mobilização e evolução. In: BEHAR, P. A. (Org.). Competência em educação a distância. Porto Alegre: Penso, 2013. p. 20-41.

BELLONI, M. L. Educação a distância e inovação tecnológica. Trabalho, Educação e Saúde, Rio de Janeiro, v. 3, n. 1, p. 187-198, mar. 2005. Disponível em: <http://www.scielo.br/pdf/tes/v3n1/10.pdf > . Acesso em: 24 fev. 2015.

BELSHAW, D. What is 'digital literacy'?: a pragmatic investigation. 2012. 274 f. Tese (Doutorado em Educação) - Departamento de Educação, Universidade de Durham, Durham, 2012. Disponível em: <http://etheses. dur.ac.uk/3446/> Acesso em: 20 ago. 2016.

BLACKMORE, S. The meme machine. Oxford: Oxford University Press, 1999.

BORGMAN, C. L. Scholarship in the digital age: information, infrastructure, and the internet. Cambridge: MIT Press, 2007.

BRASIL. Lei no 9.394, de 20 de dezembro de 1996. Estabelece as Diretrizes e Bases da Educação Nacional. Diário Oficial da União, Brasília, 23 dez. 1996. Seção 1, p. 27833.

CAPUCHINHO, C. Um em cada sete jovens conclui ensino superior no Brasil, aponta IBGE. 2014. Disponível em: <http://ultimosegundo. ig.com.br/educacao/2014-12-17/um-em-cada-sete-jovens-conclui-ensinosuperior-no-brasil-aponta-ibge.html> Acesso em: 18 ago. 2016. 
CARR, N. Is Google making us stupid?: what the internet is doing to our brains. Yearbook of the National Society for the Study of Education, Chicago, v. 107, n. 2, p. 89-94, out. 2008. Disponível em: <http://onlinelibrary.wiley.com/doi/10.1111/j.17447984.2008.00172.x/full>. Acesso em: 20 ago. 2016.

COSTA, P.; BIANCHINI, D. Caracterização da demanda futura de usuários da internet no Brasil: uma contribuição para o desenvolvimento de políticas governamentais de inclusão digital e acesso à internet. JISTEM: Journal of Information Systems and Technology Management, São Paulo, v. 5, n. 1, p. 135-162, 2008. Disponível em: <http://www.scielo.br/pdf/jistm/v5n1/08.pdf >. Acesso em: 12 maio 2016.

FRANCO, C. P. Understanding digital natives' learning experiences. Revista Brasileira de Linguística Aplicada, Belo Horizonte, v. 13, n. 2, p. 643-658, jun. 2013. Disponível em: <http://www.scielo.br/pdf/rbla/ v13n2/aop0513.pdf >. Acesso em: 27 mar. 2017.

GASQUE, K. C. G. D. Arcabouço conceitual do letramento informacional. Ciência da Informação, Brasília, v. 39, n. 3, p. 83-92, set./dez. 2010. Disponível em: <http://www.scielo.br/pdf/ci/v39n3/ v39n3a07.pdf >. Acesso em: 13 jun. 2016.

GILLEN, J. K. "A day in the life": a still developing methodology. In: EUROPEAN COOPERATION IN SCIENCE AND TECHNOLOGY PROJECT MEETING, 3., 2016, Larnaca. The digital literacy and multimodal practies of young children. Bruxelas: COST, 2016. Disponível em: <http://eprints.lancs.ac.uk/78524/2/A_Day_in_the Life_intro_paper_COST.pdf $>$. Acesso em: 20 ago. 2016.

GRIFOLL, J. et al. Quality assurance of e-learning. Helsinki: European Association for Quality Assurance in Higher Education, 2010.

Disponível em: <http://www.enqa.eu/indirme/papers-and-reports/ workshop-and-seminar/ENQA_wr_14.pdf>. Acesso em: 21 out. 2015.

IDC BRASIL. Previsão da IDC para o mercado de TIC no Brasil em 2016 aponta crescimento de 2,6\%. São Paulo, 2016. Disponível em: $<$ http://br.idclatin.com/releases/news.aspx?id=1970>. Acesso em: 20 jul. 2016.

JENKINS, H. Cultura da convergência. 2. ed. São Paulo: Aleph, 2010.

KLEIMAN, A. B. Letramento na contemporaneidade. Bakhtiniana: Revista de Estudos do Discurso, São Paulo, v. 9, n. 2, p. 72-91, ago./ dez. 2014. Disponível em: <http://www.scielo.br/pdf/bak/v9n2/ a06v9n2.pdf >. Acesso em: 12 maio 2016. 
LEMOS, A. Cibercultura: tecnologia e vida social na cultura

contemporânea. 3. ed. Porto Alegre: Sulina, 2007.

LÉVY, P. As tecnologias da inteligência: o futuro do pensamento na era da informática. Rio de Janeiro: Editora 34, 2008.

LÉVY, P. A inteligência coletiva: por uma antropologia do ciberespaço.

São Paulo: Loyola, 2010.

MiCARELlO, H. A. L. S.; MAGALHAES, T. G. Letramento, linguagem e escola. Bakhtiniana: Revista de Estudos do Discurso, São Paulo, v. 9, n. 2, p. 150-163, ago./dez. 2014. Disponível em: <http://www.scielo.br/ pdf/bak/v9n2/a10v9n2.pdf>. Acesso em: 27 mar. 2017.

PORTAL BRASIL. Mulheres são maioria no ingresso e na conclusão de cursos superiores. 2015. Disponível em: <http://www.brasil.gov.br/ educacao/2015/03/mulheres-sao-maioria-no-ingresso-e-na-conclusao-decursos-superiores >. Acesso em: 18 ago. 2016.

PRENSKY, M. Digital natives, digital immigrants. On the horizon, San Francisco, v. 9, n. 5, p. 1-6, out. 2001. Disponível em: <https://www. marcprensky.com/writing/Prensky\%20-\%20Digital\%20Natives,\%20 Digital\%20Immigrants\%20-\%20Part1.pdf>. Acesso em: 20 ago. 2016.

PROULX, S. Trajetórias de uso das tecnologias de comunicação: as formas de apropriação da cultura digital como desafios de uma sociedade do conhecimento. Trabalhos em Linguística Aplicada, Campinas, v. 49, n. 2, p. 443-453, 2016. Disponível em: <http://periodicos.sbu.unicamp.br/ ojs/index.php/tla/article/view/8645270> Acesso em: 20 ago. 2016.

RIBEIRO, A. C. R.; BEHAR, P. A. Competências para o letramento digital. In: BEHAR, P. A. (Org.). Competência em educação a distância. Porto Alegre: Penso, 2013. p. 211-222.

RICOY, M. C.; COUTO, M. J. V. S. As boas práticas com TIC e a utilidade atribuída pelos alunos recém-integrados na universidade. Educação e Pesquisa, São Paulo, v. 40, n. 4, p. 897-912, out./dez. 2014. Disponível em: <http://www.scielo.br/pdf/ep/v40n4/aop1422.pdf>. Acesso em: 12 maio 2016.

ROJO, R. Letramentos múltiplos, escola e inclusão social. São Paulo: Parábola, 2009.

SILVA, S. P. Letramento digital e formação de professores na era da web 2.0: o que, como e por que ensinar? Hipertextus Revista Digital, Recife, n. 8, jun. 2012. Disponível em: <http://www.hipertextus.net/ 
volume8/01-Hipertextus-Vol8-Solimar-Patriota-Silva.pdf >. Acesso em: 11 ago. 2016

TENREIRO-VIEIRA, C.; VIEIRA, R. M. Literacia e pensamento crítico: um referencial para a educação em ciências e em matemática. Revista Brasileira de Educação, Rio de Janeiro, v. 18, n. 52, p. 163-188, jan./mar. 2013. Disponível em: <http://www.scielo.br/pdf/rbedu/v18n52/10.pdf>. Acesso em: 20 ago. 2016.

WARSCHAUER, M. Tecnologia e inclusão social: a exclusão digital em debate. Tradução Carlos Szlak. São Paulo: Senac, 2006.

ZHAO, P.; KYNÄSHLAHTI, H.; SINTONEN, S. A qualitative analysis of the digital literacy of arts education teachers in Chinese junior high and high schools. Journal of Librarianship and Information Science, jul. 2016. Disponível em: <http://lis.sagepub.com/content/ea rly/2016/07/08/0961000616658341.abstract>. Acesso em: 20 ago. 2016.

Recebido em 20 de outubro de 2016.

Solicitação de correções em $1^{\circ}$ de fevereiro de 2017.

Aprovado em 25 de abril de 2017. 